\title{
A organização da Atenção Primária à Saúde de Belo Horizonte no enfrentamento da pandemia COVID-19: relato de experiência
}

Fabiano Gonçalves Guimarães, Taciana Malheiros Lima Carvalho, Renata Mascarenhas

Bernardes, Jackson Machado Pinto

\section{RESUMO}

Este artigo apresenta as ações desenvolvidas pela Secretaria Municipal de Saúde de Belo Horizonte/MG (SMSA-BH), para o enfrentamento da pandemia da COVID-19, destacando o papel da Atenção Primária à Saúde (APS) e sua atuação sistêmica e articulada ao Sistema Único de Saúde e às representações sociais.

Palavras-chave: Atenção Primária à Saúde; COVID-19; Pandemia.

\section{ABSTRACT}

This article presents the actions developed by the SMSA in Belo Horizonte, MG, to face the COVID-19, highlighting the role of Primary Health Care and its systemic and articulated action to the SUS and social representations.

Keywords: Primary Health Care; COVID-19; Pandemics.
Revista da Rede APS 2020

Publicada em: 09/06/2020

DOI:10.14295/aps.v2i2.128

Fabiano Gonçalves Guimarães Taciana Malheiros L. Carvalho Renata Mascarenhas Bernardes Jackson Machado Pinto (Secretaria Municipal de Saúde, Belo Horizonte, MG, Brasil)

Correspondência para:

Fabiano Gonçalves Guimarães fabiano.goncalves@pbh.gov.br

Taciana Malheiros L. Carvalho tacianamalheiros@pbh.gov.br

Renata Mascarenhas Bernardes renata.mascarenhas@pbh.gov. $\underline{b r}$

Jackson Machado Pinto jackson.machado@pbh.gov.br

A Editoria Científica agradece à Valentina Martufí (ISC/UFBA) pelo apoio à edição deste artigo. 


\section{SMSA-BH E AS PRINCIPAIS FRENTES PARA O ENFRENTAMENTO DA COVID-}

\section{9}

O enfrentamento da pandemia da COVID-19 pela SMSA-BH teve início ainda em janeiro de 2020. As notícias da existência de uma doença respiratória diagnosticada na China que atraía a atenção do mundo, trouxe imediatamente preocupação que levou ao planejamento para a revisão dos planos de contingência municipais. No dia 17 de março de 2020, Belo Horizonte registrou o início da transmissão comunitária da COVID-19 e havia 10 casos confirmados. A Prefeitura instalou um Comitê de Enfrentamento da COVID-19 para assessorar a tomada de decisões do Prefeito da Capital, determinou a suspensão das aulas nas Escolas Municipais e decretou fechamento do comércio a partir de 20 de março de 2020.

\section{i) Integração entre Assistência e Vigilância}

O fortalecimento da integração da Assistência e Vigilância foi primordial em todos os processos, instituindo um Grupo de Trabalho (GT) com a participação das equipes do Subsecretaria de Assistência à Saúde (SUASA) e Subsecretaria de Promoção e Vigilância à Saúde (SUPVISA), com reuniões semanais, que depois passaram a ser três vezes por semana. O propósito deste GT, constituído por gestores das duas áreas e com o suporte da área de Epidemiologia, foi discutir e definir ações de forma conjunta. O GT também serviu para o desenvolvimento de notas técnicas, fluxos e protocolos, e para a programação e o alinhamento das capacitações para as equipes locais.

\section{ii) Capacitação e contratação de profissionais}

Considerando a amplitude da rede de APS de $\mathrm{BH}$, com 152 centros de saúde, 588 Equipes de Saúde da Família (ESF) e aproximadamente 12 mil profissionais envolvidos garantir a capacitação e a atualização das diretrizes institucionais foi um grande desafio, representada pelo necessidade de garantir o distanciamento e afastamento social, a
Secretaria de Saúde conseguiu organizar uma série de capacitações online, incluindo vídeos de treinamento rápido e webconferências, direcionadas tanto a gerentes quanto a profissionais de saúde. No contexto da APS destacam-se três: uma capacitação das equipes assistenciais da APS nas 09 regionais de saúde, sobre o funcionamento dos centros de saúde, os fluxos de entrada e o funcionamento das atividades eletivas durante a pandemia; outra sobre Asma e síndromes respiratórias agudas: diagnóstico diferencial; e a terceira, realizada com a Gerência de Atenção Primária à Saúde (GEAPS) e a Gerência de Urgência, para discutir a síndrome respiratória aguda grave. Esta última foi fundamental para abordar um temor sentido pelos profissionais de APS no Brasil todo: Quais os procedimentos se tivermos um quadro de síndrome respiratória aguda grave (SRAG) com necessidade de intubação dentro da APS. As discussões com as equipes da Gerência de Urgência e Emergência e do Serviço de Atendimento Móvel de Urgência (SAMU) levaram a Secretaria a se responsabilizar para que o SAMU chegue com tempo suficiente para que o paciente seja intubado por um profissional mais experiente, logo mais habituado a esta tarefa.

Importante destacar que de março até o dia 28 de maio foram contratados 1.609 profissionais entre recomposição das Equipes de Saúde da Família, equipes dos serviços de urgência e incremento de profissionais para garantir as estratégias implementadas e segurança assistencial. A SMSA garantiu que todos os trabalhadores acima de 60 anos, gestantes e com doenças imunossupressoras fossem afastados preventivamente do trabalho.

\section{iii) Organização do fluxo assistencial para atendimento na APS}

Durante a pandemia, os Centros de Saúde da Capital foram orientados a separar pacientes com sintomas respiratórios na porta de entrada do serviço. Em Belo Horizonte um profissional técnico de enfermagem trabalha na prérecepção que recebe as pessoas que procuram o 
serviço para entender o motivo da visita e orientá-las. Este trabalhador é essencial para organizar a porta de entrada e direcionar o fluxo dos pacientes. A pré-recepção durante a pandemia vem buscando identificar desde a entrada pessoas com sintomas respiratórios, dor de garganta, ou dificuldade respiratória, com ou sem febre, com início nos últimos 7 dias. Dependendo das respostas, cada usuário pode ser direcionado para uma de duas portas: os usuários sem sintomas procedem para a ala de não-sintomáticos, e os usuários com sintomas vão para um local específico da recepção, separado, onde vão receber uma máscara cirúrgica, ser orientados sobre etiqueta da tosse e higienização das mãos, e instruídos de manterem distanciamento dos outros usuários presentes, e não permanecerem na unidade além do suficiente para ser atendidos. Daí são encaminhados para um setor específico, onde serão atendidos preferencialmente pelos profissionais (médico e enfermeiro) da sua equipe de saúde da família. Este atendimento envolve uma avaliação de risco do paciente, para determinar se o paciente apresenta um caso leve, ou um caso suspeito de SRAG.

No primeiro caso, o paciente vai receber um tratamento sintomático e será orientado de retornar para casa com máscara, evitando transporte público e aglomerações, e de praticar o isolamento domiciliar por no mínimo 7 dias para o portador dos sintomas, e 14 dias para os comunicantes. Antes de sua saída, anota-se o contato para poder começar o telemonitoramento, e recomenda-se o retorno em caso de sinais de agravamento. Os profissionais realizam a notificação, e registram o paciente no prontuário eletrônico.

Na suspeita de SRAG, pactuou-se o acionamento do SAMU, buscando agilizar o processo e diminuir o risco de contaminação. Enquanto aguardam a chegada do SAMU, os profissionais do CS realizam medidas de suporte para estabilização clínica. Após a entrega do paciente para o SAMU, registram o mesmo no prontuário eletrônico, e na planilha de casos suspeitos de SRAG.
O Telemonitoramento dos casos classificados como leve são feitos pelas Equipes de Saúde da Família e os casos de contatos dos pacientes suspeitos de SRAG pela equipe técnica da Gerência de Assistência Epidemiologia e Regulação (GAERE).

\section{iv) Abertura do Centro Especializado de Coronavírus}

Embora cada Centro de Saúde de Belo Horizonte estivesse capacitado para atender pacientes suspeitos da infecção pelo Novo Coronavírus, foram criados dois Centros Especializados para atendimento da COVID-19 (CECOVID). O primeiro CECOVID começou a funcionar na região central da cidade (UPA Centro Sul) no dia 3 de março. No final do mesmo mês, em 25 de março, criou-se o segundo centro em uma das regionais mais populosas e mais distantes do centro (UPA Venda Nova). Estes centros, equipados com médico, enfermeiro, técnico de enfermagem, auxiliar administrativo e de serviços gerais, inicialmente faziam atendimentos a demanda espontânea de pessoas com sintomas de doenças respiratórias e coleta de material para realização de exame. Até o dia 04 de junho os dois CECOVID atenderam um total de 5.157 pessoas. A existência de um centro dedicado ao atendimento a pessoas com suspeita de COVID 19 foi muito importante no primeiro momento da epidemia, quando ainda não estava estabelecida a transmissão comunitária. A identificação dos casos para vigilância epidemiológica foi essencial para o controle da disseminação do vírus no município.

\section{v) Teleatendimento}

No dia 6 de abril, foi lançada a Consulta online para casos suspeitos da COVID-19, realizada por especialistas da rede secundária do SUS BH que estavam com uma redução de $80 \%$ nas consultas em decorrência do cenário de isolamento social. A UNIMED, parceira nesta iniciativa, disponibilizou gratuitamente à prefeitura a sua plataforma e software de consulta, facilitando o contato paciente-médico através de câmera e som. $\mathrm{O}$ acesso à plataforma é realizado através 
de site da $\quad$ Prefeitura (www.consultacoronavirusbh.com.br), onde o usuário entra, digita seu nome, faz um cadastro simples, e é direcionado para uma tela para verificar se tem cadastro no Centro de Saúde. Caso não haja o cadastro, o usuário é orientado a procurar a APS. Após a inserção dos dados a agenda é aberta para que a consulta seja marcada, com dia e hora de sua preferência.

Até o dia 06 de junho foram realizados 3.516 agendamentos, sendo uma importante oferta para os usuários cadastrados no SUS em BH, disponibilizando 400 vagas diariamente. Após a consulta uma equipe de telemonitoramento acompanha os pacientes atendidos via telefone.

\section{vi) Insumos para controle e prevenção}

Os insumos para controle e prevenção, os Equipamentos de Proteção Individual (EPI), foi um grande desafio de todos os serviços de saúde no início da pandemia da COVID-19. Em Belo Horizonte não foi diferente. $O$ medo do contágio levou à explosão do consumo de EPI na rede assistencial além da grande dificuldade em encontrar fornecedores. A área de compras da SMSA em conjunto com a área técnica desenvolveu uma intensa agenda visando a aquisição dos insumos de forma transparente, ágil e dentro da legislação dos processos licitatórios. No dia 23 de abril foi publicada nota técnica com orientações sobre uso de EPI que regulamentou o uso racional explicitando em cada local, como, qual EPI e quando deveriam ser distribuídos e utilizados, garantindo a segurança do profissional e paciente. Neste período toda a rede assistencial já havia recebido vídeos de treinamento sobre paramentação e desparamentação. Em conjunto com este processo, foi criada uma ferramenta importante de gestão para o levantamento do redimensionamento dos insumos garantindo a provisão necessária para a rede.

\section{vii) Testagem de profissionais de saúde}

Desde o começo estabeleceu-se também um serviço exclusivo para atendimento de trabalhadores da saúde de $\mathrm{BH}$ com suspeita da
COVID-19 no Centro de Referência em Saúde do Trabalhador. O serviço acolhe, notifica e realiza a coleta para teste RT PCR de todos os trabalhadores que atuam na assistência (serviços públicos e privados) que apresentem sintomas. Até o dia 03 de junho foram realizados exames RT-PCR em 2198 profissionais de saúde, sendo 123 testes positivos, 5,6\% de positividades. Uma das explicações para a baixa positividade é o investimento feito pela secretaria municipal de saúde para a oferta de EPIs de forma adequada, a atualização constante de notas técnica e vídeos orientativos. Uma outra hipótese é o receio das pessoas de estarem contaminadas levando ao aumento da procura. Outra explicação, que necessitaria maiores dados para ser confirmada, é que o contágio entre profissionais de saúde de $\mathrm{BH}$ seja baixo por pouca circulação do vírus. A partir da segunda quinzena de junho será implantado o laboratório biologia molecular, com foco essencial na avaliação diagnóstica de vírus respiratórios, neste momento, essencialmente na identificação do SARS-Cov-2. O laboratório contará com equipamentos de conhecida qualidade e específicos para a análise de Biologia Molecular-RT-PCR e se somará aos demais laboratórios da Rede Municipal, um apoio fundamental para responder a necessidade de ampliar a rede de diagnóstico e de controle da COVID19.

\section{viii) Infraestrutura}

Os recursos humanos não foram os únicos que precisaram ser reforçados e a Prefeitura de Belo Horizonte investiu na melhoria da infraestrutura e ambiência de recepção das Unidades de Pronto Atendimento (UPAs), com tendas externas dedicadas à separação do fluxo de sintomáticos respiratórios dos outros usuários. Também houve um investimento em transporte sanitário, aumentando as ambulâncias SAMU descentralizadas na cidade. Em termos de ocupação de leitos de UTI, o município tem tido uma baixa ocupação de leitos de UTI e enfermarias exclusivos para COVID-19, com taxas de $59 \%$ e $48 \%$, respectivamente (dados de 31 de maio). Sabemos que este dado é dinâmico 
e sofre alteração todos os dias. Foram habilitados junto ao Ministério da Saúde 342 novos leitos UTI e remanejamento de 346 leitos UTI, com o total de 1.752 leitos de enfermaria COVID.

\section{ix. Ações de comunicação}

Quanto às ações de comunicação, a Prefeitura realiza atualização diária da página no portal da $\mathrm{PBH}$

(https://prefeitura.pbh.gov.br/saude/coronavir us), com todas as notas técnicas e informações sobre o Coronavírus atualizadas, incluindo boletim epidemiológico publicado diariamente. Outro espaço potente de comunicação é o "Acontece Saúde", publicação semanal que tem a função de informar a rede sobre as experiências exitosas realizadas. Até o final de maio, a Secretaria de Saúde publicou (27 notas técnicas, 7 fluxogramas, 7 notas informativas, 8 cartazes e materiais educativos) conforme tabela 1 a seguir.

Tabela 01 - Notas técnicas, notas informativas e fluxos publicados até 31 de maio 2020

\begin{tabular}{|c|c|c|}
\hline Data & Número documento & Descrição \\
\hline 04/03/2020 & $\begin{array}{l}\text { Ofício } \quad \mathrm{n} \text { o } \\
\text { GEAPS/DIAS/SUASA/SMSA }\end{array}$ & Informativo às escolas de Belo Horizonte sobre o Coronavírus \\
\hline 05/03/2020 & Ofício no 138/2020 - GEASF/DIAS/GELOG & Insumos para controle e prevenção da COVID-19 \\
\hline $19 / 03 / 2020$ & $\begin{array}{l}\text { Nota técnica COVID-19 no 006/2020 } \\
\text { (substitui a Nota Técnica } n^{\circ} 05 / 2020 \text { - } \\
\text { Atualizada em 08/04/2020) }\end{array}$ & $\begin{array}{l}\text { Orientações para a Vigilância Epidemiológica da COVID-19 no município } \\
\text { de Belo Horizonte. }\end{array}$ \\
\hline $19 / 03 / 2020$ & Nota técnica COVID-19 n 008/2020 & $\begin{array}{l}\text { Diretrizes para instituições que acolhem pessoas idosas em um contexto } \\
\text { de Doenças Respiratórias. }\end{array}$ \\
\hline $19 / 03 / 2020$ & $\begin{array}{l}\text { Nota técnica COVID-19 no 009/2020 } \\
\text { Atualizada em 01/04/2020 }\end{array}$ & $\begin{array}{l}\text { Recomendações para adequação das atividades desenvolvidas nos } \\
\text { dispositivos da Rede de Atenção Psicossocial (RAPS) à Saúde em situação } \\
\text { de surtos/epidemias de Síndrome Gripal e infecção pelo SARS-COV-2. }\end{array}$ \\
\hline $19 / 03 / 2020$ & Nota técnica COVID-19 n 010/2020 & $\begin{array}{l}\text { Recomendações para adequação das atividades desenvolvidas nas } \\
\text { Unidades de Pronto Atendimento (UPA) e Serviço de Atendimento } \\
\text { Móvel de Urgência (SAMU) de Belo Horizonte para atendimento em } \\
\text { situações de surtos/epidemias de Síndrome Gripal (SG), Síndrome } \\
\text { Respiratória Aguda Grave (SRAG) e infecção pela COVID-19 (Coronavírus } \\
\text { 19). }\end{array}$ \\
\hline $27 / 03 / 2020$ & 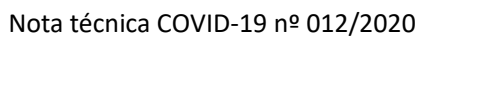 & $\begin{array}{l}\text { Recomendações para atendimento às gestantes, parturientes e } \\
\text { puérpera em situação de surtos/epidemias de Síndrome Gripal e } \\
\text { infecção pelo SARS-CoV- } 2 \text {. }\end{array}$ \\
\hline $31 / 03 / 2020$ & Fluxo COVID-19 no 001/2020 & $\begin{array}{l}\text { Fluxo para coleta e transporte de espécime clínico para diagnóstico } \\
\text { etiológico em HOSPITAIS, em situação de surtos/epidemias de Síndrome } \\
\text { Gripal e infecção pelo SARS-CoV-2. }\end{array}$ \\
\hline
\end{tabular}




\begin{tabular}{|c|c|c|}
\hline $31 / 03 / 2020$ & Fluxo COVID-19 no 003/2020 & $\begin{array}{l}\text { Fluxo dos resultados dos exames de espécime clínico para diagnóstico } \\
\text { etiológico em profissionais de saúde atuantes no município, em situação } \\
\text { de surtos/epidemias de Síndrome Gripal e infecção pelo SARS-CoV-2. }\end{array}$ \\
\hline $01 / 04 / 2020$ & Nota técnica COVID-19-nㅇ 013/2020 & $\begin{array}{l}\text { Recomendações do Município de Belo Horizonte para adequação das } \\
\text { ações de vigilância e controle de zoonoses frente à atual situação } \\
\text { epidemiológica referente ao Coronavírus (COVID-19). }\end{array}$ \\
\hline $03 / 04 / 2020$ & Nota Informativa COVID-19 n002/2020 & $\begin{array}{l}\text { Orientações sobre o cuidado à pessoa idosa em contexto de pandemia } \\
\text { de coronavírus (COVID-19) para população em geral e profissionais de } \\
\text { saúde. }\end{array}$ \\
\hline $08 / 04 / 2020$ & Nota técnica COVID-19 no 015/2020 & $\begin{array}{l}\text { Recomendações para adequação das atividades da Casa de Apoio Nossa } \\
\text { Senhora da Conceição no município de Belo Horizonte em situação de } \\
\text { surtos/epidemias de Síndrome Gripal e infecção pelo SARS-CoV-2. }\end{array}$ \\
\hline 08/04/2020 & Nota Informativa COVID-19 n003/2020 & Orientações aos profissionais da construção civil. \\
\hline Não se aplica & Cartaz & Cartaz sobre os cuidados de higiene. \\
\hline Não se aplica & Cartaz & Cartaz com informações gerais sobre COVID-19 \\
\hline Não se aplica & Cartaz & $\begin{array}{l}\text { Salve vidas higienize suas mãos: higienização das mãos com preparações } \\
\text { alcoólicas a } 70 \%\end{array}$ \\
\hline Não se aplica & Cartaz & Previna infecções com higienização das mãos (água e sabão) \\
\hline 03/03/2020 & Vídeo & Vídeo orientações sobre o Coronavírus \\
\hline $29 / 03 / 2020$ & Vídeo & Higienização das mãos \\
\hline
\end{tabular}

Fonte: elaborado pelo autor.

Os temas foram os mais variados: desde o funcionamento da APS durante a pandemia e coletas de exames dos profissionais de saúde, passando por ações de zoonose durante esse período, uso e manutenção de máscaras artesanais, e incluindo o cuidado nas vilas, comunidades e favelas. Esta última foi desenvolvida em conjunto pela GEAPS e Equipes de Saúde atendendo nessas áreas, assistentes sociais, e representantes das comunidades, e busca dialogar com as comunidades sobre os cuidados em tempos de COVID-19, tentando trazer referências culturais relevantes. Nestes esforços a PBH juntou-se numa parceria com a imprensa para conseguir divulgar as informações até a população. A página tem sido 
fonte de consulta para a população em geral, para os trabalhadores de saúde e para outros municípios.

\section{x) Ações de cuidado para as populações em situação de rua}

A pandemia COVID-19 e sua progressão em Belo Horizonte mobilizou diversas organizações sociais e políticas públicas no cuidado especialmente da população em situação de rua (PSR), dada as especificidades desse segmento populacional cuja história de vida, modo de viver e circular pela cidade contribuem para aumento da fragilidade, vulnerabilidades sociais e suscetibilidade ao adoecimento. Em relação ao cuidado assistencial, a atuação da APS é essencial para garantir o acesso oportuno para esta população, que muitas vezes possui um caráter nômade pela cidade. Garantir a porta aberta para a população que mais precisa e no momento que a mesma procura, mesmo sem cadastro é uma diretriz colocada em todas as discussões com os gestores locais.

A Prefeitura de Belo Horizonte trabalhou em ações sociais voltadas para as populações mais vulneráveis da cidade. Organizou a distribuição de cestas básicas e kits de higiene para mais de 57 mil famílias, além de cerca de 3 mil sabonetes entregues para a população em situação de rua, após a instalação de pias para lavagem das mãos em pontos estratégicos e com maior concentração de pessoas em situação de rua. Também foi realizado distribuição de máscaras em tecido para a população em área de vilas e favelas pelos Agentes Comunitários de Saúde e Agentes de Combate a Endemias, como oportunidade de uma ação de vigilância e educação em saúde no momento de cada entrega.

Outra iniciativa direcionada especificamente à população em situação de rua, foi a criação de um serviço provisório e emergencial em parceria com a política pública de assistência social, SMSA e o Serviço Social do Comércio (SESC MG). A estrutura foi montada com 260 acomodações individuais com banheiro privativo e inaugurada no dia 06 de abril. É a partir da APS, coordenadora do cuidado, que os casos são identificados. A pessoa em situação com sintomas respiratórios sem critério para hospitalização e sim, de cuidados básicos e isolamento social é direcionado para o serviço, para cumprir os 14 dias de isolamento a partir dos primeiros dias de sintomas. Todos os casos que estão em isolamento são acompanhados diariamente pelo centro de saúde do território, e até o dia 01 de junho foram acolhidas 116 pessoas.

\section{xi). Ações de cuidado para a população de idosos em Instituições de Longa Permanência para Idosos (ILPI)}

Com o objetivo de reduzir a morbimortalidade pela Covid-19 nas ILPI, a Secretaria de Saúde de Belo Horizonte - SMSA-BH, a Secretaria Municipal de Assistência Social, Segurança Alimentar e Cidadania - SMASAC-BH e o Núcleo de Geriatria e Gerontologia do Hospital das Clínicas UFMG/ Centro Mais Vida articularam uma atenção específica para as ILPI conveniadas e as que apresentam maior vulnerabilidades, totalizando 91 instituições e cerca de 1800 idosos. Em Belo Horizonte existem 208 instituições, das quais 180 são privadas e 28 filantrópicas, sendo 24 destas conveniadas com a Prefeitura. O Centro Mais Vida HC/UFMG fará o telemonitoramento diário dos residentes por meio de chatbot que será alimentado pela equipe técnica da ILPI. Será através do telemonitoramento que as equipes de geriatras na identificação de qualquer quadro suspeito de COVID 19 acionará imediatamente a APS para que as ações em saúde e de proteção aos idosos seja realizada. Um dos grandes desafios em uma ILPI é a garantia de espaço para a realização do isolamento frente a um caso suspeito. Foi pensando nisso, que que no dia 01 de junho foi implantado a Unidade de Acolhimento Provisório de Idosos (UAPI), onde a APS irá após avaliação, encaminhar o idoso suspeito de COVID sem critérios de hospitalização de ILPI e sem condições de isolamento, além da oferta de testagem de todos os idosos sintomáticos de ILPI. 


\section{xii) Cuidado na APS aos usuários com condição crônica de risco}

Um bom exemplo da importância de manter-se flexível enquanto às medidas e protocolos foi o cuidado aos usuários com doenças crônicas. A reação inicial ao estado de pandemia foi de instruir os pacientes do grupo de risco que ficassem em casa e procurassem os CS apenas em caso de algo de grave. Durante os meses de março e abril houve uma importante queda no número de atendimentos nos CS e UPA, e as autoridades sanitárias locais agora temem uma onda de complicações e problemas relacionados ao descontrole de doenças crônicas. Já estão vendo indícios, como um aumento de mais de $20 \%$ em óbitos domiciliares - testados por COVID-19 e resultados negativos. Portanto, a SMSA-BH criou um programa de controle de crônicos, com um Fluxograma de Monitoramento de Crônicos na APS. A GEAPS fez uma lista com todos os usuários com condições crônicas e alto risco que no primeiro momento incluiu todos os pacientes com diabetes tipo 1 , pacientes com diabetes tipo 2 que tenham complicação clínica, cardiopatas e usuários de anticoagulante. A despeito de ser esperado que as Equipes de Saúde da Família já trabalhem com planilhas de acompanhamento de crônicos, optou-se pelo envio de uma planilha pela GEAPS devido à heterogeneidade de formação dos profissionais da Rede.

Espera-se com essa proposta auxiliar as equipes da APS de Belo Horizonte na organização do cuidado aos usuários com condições crônicas, considerando o contexto da pandemia de SARSCoV-2. A iniciativa de Sistematizar uma proposta para acompanhamento dos usuários com alto risco cardiovascular pretende ser um ponto de partida para ações, que poderão ser ampliadas para outros grupos populacionais. 0 delineamento da proposta pode ser vista no fluxograma 1.

\section{CONSIDERAÇõES FINAIS}

À luz desta experiência, algumas reflexões são importantes. Primeiro, a importância da atenção primária fortalecida, priorizada pela gestão municipal e engajada nos processos de cuidado aos usuários. Outro ponto importante foi a teleconsulta que nos mostra que veio para ficar e que agora é o momento de incentivar essa prática no dia a dia da APS, tanto com pacientes com COVID-19, quanto com os crônicos. Este é um legado que a pandemia deixará. Belo Horizonte está se movimentando para viabilizar as certificações digitais, para tornar mais eficiente o sistema de teleconsultas.

Importante destacar a APS como tendo o papel neste momento de identificar precocemente os casos, ser muito resolutiva nos casos leves e encaminhar rápida e corretamente os casos graves. As medidas para enfrentar uma pandemia não são fechamento de unidades e afastamento da população, mas coordenação do cuidado e compreensão dos fluxos de atendimento na rede.

Outra lição importante sobre o papel da APS em situações como esta é a necessidade de preencher lacunas de suporte familiar e comunitário. Este é um momento difícil, de adoecimento, de perda de renda, e a porta do centro de saúde tem que ser a porta do suporte familiar e da discussão do que é importante. Além disso, os pacientes confiam que irão receber informações corretas, baseadas na ciência, pelos profissionais de saúde que atendem eles, então esse é outro papel significativo da APS. Finalmente, é fundamental que a APS contribuía para a valorização do SUS.

Por fim, há que se destacar que no enfrentamento ao maior desafio de saúde pública da nossa geração Belo Horizonte pode contar com um corpo gerencial coeso e ciente das suas responsabilidades, com um grupo de trabalhadores dedicados ao SUS e principalmente ao SUS-BH, sistema construído com muito esforço por todos que já passaram por essa rede complexa e que nos ensina a cada dia que o mais valioso são as pessoas, quem cuida e de quem cuidamos. 
Figura 01 - Fluxograma operacional para monitoramento de usuários com condições crônicas de alto risco cardiovascular na APS, durante a pandemia de SARS-CoV-2.

\section{FLUXOGRAMA PARA MONITORAMENTO DE USUÁRIOS COM CONDIÇÕES CRÔNICAS PRIORITÁRIAS NA APS, DURANTE A PANDEMIA DE SARS -COV-2}
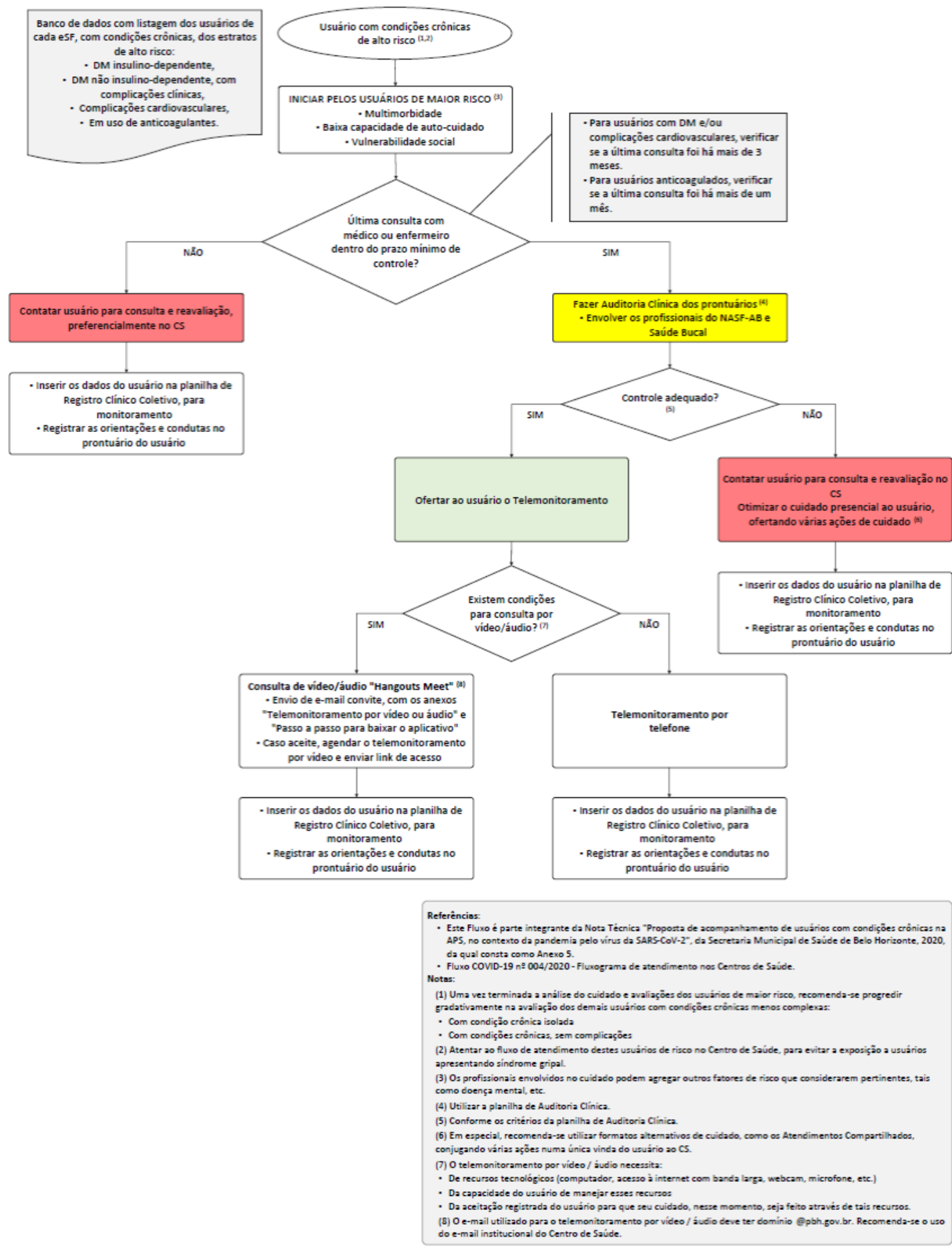